18 Piller NB, Clodius L. Clinical results of the effectiveness of Venalot in 103 postmastectomy lymphoedema patients. In: Bartos V, Davidson JW, eds. Advances in lymphology. Prague: Avicenum, 1982:475-9.

19 Piller NB, Morgan RG, Casley-Smith JR. A double-blind cross-over trial of $O$-( $\beta$-hydroxy-ethyl)-rutosides (benzo-pyrones) in the treatment of lymphoedema of the arms and legs. Br f Plast Surg 1988;41:20-7.

20 Casley-Smith JR, Casley-Smith JR. Effects of various combinations of complex physical therapy, benzo-pyrones and mercury compression on lymphoedema; which combination works best? In: Cluzan RV, Pecking AP, Lokiec FM, eds. Progress in lymphology XIII. Amsterdam: Elsevier, 1992:537-8. (Excerpta medica international congress series 994.)

21 Casley-Smith JR, Jamal S, Casley-Smith JR. Reduction of filaritic lymphoedema and elephantiasis by 5,6-benzo- $\alpha$-pyrone (coumarin) and the effects of diethylcarbamazine (DEC). Ann Trop Med Parasitol 1993;87:247-58.

22 Song JM, Ma K. [Role of low density microfilaraemia in the transmission of filariasis in areas where bancroftian filariasis is virtually eliminated.] foumal of Parasitology and Parasitic Diseases 1988;6:71. (In Chinese.)
23 Lennihan $\mathbf{R} \mathrm{Jr}$, Mackereth $M$. Calculating volume changes in a swollen extremity from surface measurements. Am $\mathcal{F}$ Surg 1973;126:649-52.

24 Stranden E. Comparison between surface measurements and water displacement volumetry for the quantification of leg edema. $f$ Oslo City Hosp 1981;31:153-5.

25 Anderson J. Filariasis in British Guiana: clinical, pathological and therapeutic investigations. London School of Tropical Medicine Research Memoires 1924;Ser 5:13-4.

26 Casley-Smith JR. Terminology for elephantiasis. In: Nishi M, Uchino S Yabuki S, eds. Progress in lymphology XII. Amsterdam: Elsevier, 1990 389-90. (Excerpta Medica international congress series 887.)

27 Yamauchi S. Lymphatic filariasis. In: Földi $M$, Casley-Smith JR, eds. Lymphangiology. Stuttgart: Schattauer, 1983:747-68.

28 Worms MJ, McLaren DJ. Macrophage-mediated damage to filarial worms. I Helminthol 1982;56:235-41.

(Accepted 20 August 1993)

\title{
Comparison of three regimens for malaria prophylaxis in travellers to east, central, and southern Africa
}

\author{
J C F M Wetsteyn, A de Geus
}

\begin{abstract}
Objectives-Confirmation of breakthroughs in three different malaria chemoprophylactic regimens (chloroquine $300 \mathrm{mg}$ weekly and proguanil $100 \mathrm{mg}$ daily; chloroquine $300 \mathrm{mg}$ weekly and proguanil 200 mg daily; proguanil $200 \mathrm{mg}$ daily) and assessment of compliance.
\end{abstract}

Design-Prospective, randomised multicentre trial.

Setting-Five vaccination centres in the Netherlands.

Subjects-Dutch travellers to east, central, and southern Africa.

Mainoutcomemeasures-Plasmodiumfalciparum seen on blood film; concentrations of drugs measured in blood spots.

Results-P falciparum infection was confirmed in $12(21 \%)$ of 58 travellers with fever suspected to be due to malaria. No difference in prophylaxis failures between the regimens was found. Breakthroughs were difficult to confirm, as compliance could be determined in only $30 \%$ of the participants with fever and chloroquine in their regimen. One breakthrough was proved. The risk per 1000 people per month for travellers was 5.4 (95\% confidence interval 2.4 to 12.6) for chloroquine $300 \mathrm{mg}$ weekly and proguanil $100 \mathrm{mg}$ daily, $2.8(0.9$ to 10.1$)$ for chloroquine $300 \mathrm{mg}$ weekly and proguanil $200 \mathrm{mg}$ daily, and $6.0(2.6$ to 14.0) for proguanil $200 \mathrm{mg}$ daily.

Conclusion-Prophylaxis failures occurred in less than $1 \%$ of the participants, and only $21 \%$ of those with a fever were suffering from falciparum malaria. Compliance was moderate. The chloroquineproguanil combination can still be recommended for visitors to east, central, and southern Africa.

Academic Medical Centre, Unit for Infectious Diseases and Tropical Medicine, Meibergdreef 9 , 1105 AZ Amsterdam, Netherlands

J C F M Wetsteyn, specialist physician tropical medicine

University of Amsterdam, Amsterdam

A de Geus, professor of

tropical medicine

Correspondence to:

Dr Wetsteyn.

$B M \mp 1993 ; 307: 1041-3$

\section{Introduction}

Since 1979 chloroquine resistant strains of Plasmodium falciparum have spread through tropical Africa. Most patients with imported malaria in industrialised countries acquire their infections in subSaharan countries. ${ }^{1-3}$ Sound advice for chemoprophylaxis is increasingly difficult to give; a balance should be made between the risk of infection, the case fatality rate, the protection afforded by preventive measures, and the possible risks of these measures. The real incidence of malaria among travellers is not known and the estimates of the risk of infection have so far been based mainly on surveillance of imported malaria. The case fatality rate of imported falciparum malaria varies between $0.6 \%$ and $7 \%{ }^{45}$ To investigate the most appropriate use of chloroquine and proguanil, which are both fairly non-toxic drugs, we conducted a prospective multicentre randomised trial among Dutch travellers to east, southern, and central Africa. The original study included travellers as well as expatriates; the preliminary data of the combined groups were reported at the second international conference on travel medicine, Atlanta, May 1992.

We compared three chemoprophylactic regimens: chloroquine $300 \mathrm{mg}$ weekly and proguanil $100 \mathrm{mg}$ daily (then the official Dutch recommendation); chloroquine $300 \mathrm{mg}$ weekly combined with proguanil $200 \mathrm{mg}$ daily (the advice in the United Kingdom and of the World Health Organisation ${ }^{67}$ ); and proguanil $200 \mathrm{mg}$ daily. The proguanil only regimen was included because a retrospective study in Dar-es-Salaam suggested good prophylactic efficacy. ${ }^{8}$

The aim of the study was to assess the efficacy of the three regimens. The objective was to confirm a breakthrough by means of a blood film containing $P$ falciparum and by assessing compliance by measuring drug concentrations in whole blood.

\section{Subjects and methods}

RECRUITMENT OF SUBJECTS

From March 1987 until November 1989 participants were enrolled at one of the five vaccination centres in the Netherlands. The central supervision and coordination was performed by JW at the Academic Medical Centre, Amsterdam.

Subjects were defined as travellers if staying abroad less than 365 days. Those originating from endemic malarious areas and those with known allergy to one of the drugs were excluded. We calculated that about 400 participants in each regimen were required to permit inferences about prophylactic efficacy, assuming one breakthrough in every 100 participants with chloroquine $300 \mathrm{mg}$ weekly and proguanil $100 \mathrm{mg}$ daily, chloroquine $300 \mathrm{mg}$ weekly and proguanil $200 \mathrm{mg}$ daily, and four in every 100 with proguanil $200 \mathrm{mg}$ daily.

\section{ALLOCATION TO REGIMENS}

Participants allocated themselves to a regimen by taking an envelope out of 99 (33 each of the three regimens). Members of one family were allocated to one regimen. The drugs had to be taken from the day before entering the malarious area until four weeks after leaving the area.

\section{INSTRUCTIONS TO PARTICIPANTS}

Each participant was provided with a booklet with information on how to deal with a possible break- 
through, with microscope slides and sterile lancets to make thick blood films, and filter paper (Whatman chromatographic) with imprinted circles to be filled up with blood from the fingerprick $(50 \mu \mathrm{l})$.

The participants received three sulfadoxinepyrimethamine tablets as standby treatment. The booklet contained a request to local physicians to confirm the diagnosis of malaria by examining the film before giving treatment and to report their findings in the booklet. If a local doctor could not be reached in time the participants were instructed to take the sulfadoxine-pyrimethamine tablets after making the films and blood spots themselves. The slides and filter papers were to be taken home or to be sent to the laboratory for tropical medicine at the Royal Tropical Institute in Amsterdam.

Four weeks after returning home the participants had to send their booklet to the Academic Medical Centre in Amsterdam. Three to five reminders were sent to participants who did not mail their booklet spontaneously.

\section{LABORATORY METHODS}

The films were examined for malaria parasites immediately after arrival. Whole blood concentrations of chloroquine and desethylchloroquine were determined from the blood spots with high pressure liquid chromatography with fluorescence detection'; the lower limit of the required chloroquine concentration was set at $0.19 \mu \mathrm{mol} / \mathrm{s}^{9}$ The determination of proguanil concentration was not feasible at the time of the study.

\section{DEFINITIONS}

Failure of prophylaxis was defined as $P$ falciparum present in the thick blood film during the period of travel and the four weeks after returning home, irrespective of compliance. Compliance with the regimen was defined as a chloroquine concentration of $>0.19 \mu \mathrm{mol} / \mathrm{l}$ determined from the blood spots prepared at the same time as the films were made.

A breakthrough was signalled by $P$ falciparum present in the thick blood film during the travel period and the four weeks after returning home despite good compliance.

\section{DATA ANALYSIS}

The incidence of prophylaxis failures in the regimens was compared by using the $\chi^{2}$ test. Significance was defined as $\mathrm{p}<0.05$.

\section{Results}

PARTICIPANTS

A total of 1625 subjects participated. Data on the 204 residents are not reported here. Of the 1421 travellers enrolled, 16 cancelled their trip or changed their destination and in $19(1.3 \%)$ the data were incomplete. Thus, 1386 travellers remained for final analysis. Of these, $911(60 \%)$ spent less than six weeks in the tropics.

RESPONSE

The booklet was returned by $1263(91 \%)$ of all

Failure of malaria prophylaxis in subjects who spent less than a year in east, central, or southern Africa

\begin{tabular}{lcccc}
\hline & $\begin{array}{c}\text { Chloroquine } \\
300 \mathrm{mg} \\
\text { weekly plus } \\
\text { proguanil } \\
100 \mathrm{mg} \text { daily }\end{array}$ & $\begin{array}{c}\text { Chloroquine } \\
300 \mathrm{mg} \\
\text { weekly plus } \\
\text { proguanil } \\
200 \mathrm{mg} \text { daily }\end{array}$ & $\begin{array}{c}\text { Proguanil } \\
200 \mathrm{mg} \text { daily }\end{array}$ & Total \\
\hline $\begin{array}{l}\text { Exposure (per 1000 person-months) } \\
\text { No of subjects }\end{array}$ & 927 & 713 & 830 & 2470 \\
$\begin{array}{l}\text { Pfalciparum present } \\
\text { Risk (per 1000 person-months) (95\% }\end{array}$ & 452 & 390 & 421 & 1263 \\
$\quad$ confidence interval) & 5 & 2 & 5 & 12 \\
\hline
\end{tabular}

travellers and by $830(91 \%)$ of the 911 travellers who spent less than six weeks abroad. The proportion on each regimen was not different among the travellers who did and did not respond: $452 / 497$ (91\%) for chloroquine $300 \mathrm{mg}$ weekly plus proguanil $100 \mathrm{mg}$ daily; 390/423 (92\%) for chloroquine $300 \mathrm{mg}$ weekly plus proguanil $200 \mathrm{mg}$ daily; and $421 / 466(90 \%)$ for proguanil $200 \mathrm{mg}$ daily.

\section{FAILURE OF PROPHYLAXIS}

Twelve $(21 \%)$ of 58 travellers with a fever had falciparum malaria (nine of 54 blood films examined in Amsterdam and three of the four examined abroad contained $P$ falciparum). Three of these attacks occurred within six weeks of starting prophylaxis. Eight $(18 \%)$ of 46 travellers who became ill in the tropics and four (33\%) of 12 who fell ill after returning home were suffering from falciparum malaria. Five had taken chloroquine $300 \mathrm{mg}$ weekly and proguanil $100 \mathrm{mg}$ daily, two had taken chloroquine $300 \mathrm{mg}$ weekly and proguanil $200 \mathrm{mg}$ daily, and five had taken proguanil $200 \mathrm{mg}$ daily $(\mathrm{p}>0.05)$.

Seventeen of the 830 travellers who stayed less than six weeks abroad had a fever. In three patients $P$ falciparum was found; one had been taking chloroquine $300 \mathrm{mg}$ weekly and proguanil $100 \mathrm{mg}$ daily, and two had been taking proguanil $200 \mathrm{mg}$ daily.

\section{COMPLIANCE}

Assessing compliance was possible for chloroquine users only; it was not possible to determine reliable proguanil concentrations from the blood spots on filter paper. Thirty nine of the 58 travellers with an assumed breakthrough were chloroquine users ( 25 used chloroquine $300 \mathrm{mg}$ weekly and proguanil $100 \mathrm{mg}$ daily, 14 chloroquine $300 \mathrm{mg}$ with proguanil $200 \mathrm{mg}$ ). No filter paper was received from 13 and a test was not possible in a further 13 (the spots contained $<50 \mu l$ blood, or blood could not be extracted from the filter paper). Six of the remainder were found to have $\geqslant 0.19 \mu \mathrm{mol} / \mathrm{l}$ of chloroquine and seven had $<0 \cdot 19 \mu \mathrm{mol} / \mathrm{l}$.

\section{BREAKTHROUGHS}

Compliance could be determined in three of the seven travellers with falciparum malaria and chloroquine in their regimen. The chloroquine concentration in whole blood was $\geqslant 0.19 \mu \mathrm{mol} / /$ in one patient and $<0.19 \mu \mathrm{mol} / \mathrm{l}$ in two patients.

\section{RISK OF PROPHYLAXIS FAILURE}

The number of person-months of exposure for each regimen was calculated by counting the months of exposure of every traveller on that regimen known to have returned from Africa $(n=1263)$. The table gives the risks of a failure in travellers who spent less than a year abroad. For those who spent less than six weeks abroad the risk was $4 \cdot 0 / 1000$ person-months $(95 \%$ confidence interval: 0.56 to 28 ) for chloroquine $300 \mathrm{mg}$ weekly and proguanil $100 \mathrm{mg}$ daily and $7 \cdot 9 / 1000$ person-months ( $2 \cdot 0$ to 31 ) for proguanil $200 \mathrm{mg}$ daily. The risks were not significantly different between the regimens nor for length of travel (all travellers $v$ those travelling $<6$ weeks).

\section{Discussion}

Because prophylaxis failures were analysed sequentially, after 2.5 years it was apparent that the original assumptions of expected failures were wrong. A much greater number of participants would be required to attain a significant difference between the regimens. Even more importantly, it seemed at this time that the slight differences between the regimens would not be sufficient to alter the national recommendations for chemoprophylaxis. 
In our study falciparum malaria could be confirmed in only 12 of the 58 patients suffering from a fever assumed to be malaria-that is, less than $\cdot 1 \%$ of all participants. No difference in prophylaxis failures between the regimens was found. The risk in our study is comparable to that found in studies among travellers who used chemoprophylaxis by Lobel et al for different parts of Kenya (0.7-10 per 1000 person-months) ${ }^{10}$ and by Steffen et al, who calculated a risk of 5.5 per 1000 person-months for travellers to east Africa. ${ }^{11}$ In our study the risk in those who travelled for less than six weeks was not significantly different from the risk for all travellers. In the study of Fogh et al $P$ falciparum was found in the thick blood film of $4(1 \%)$ of 384 participants taking chloroquine $300 \mathrm{mg}$ weekly and proguanil $200 \mathrm{mg}$ daily. ${ }^{12}$ Their study population, consisting of $95 \%$ travellers (of whom $70 \%$ spent less than four weeks abroad) and 5\% residents, is comparable with that in our study.

\section{COMPLIANCE}

For comparison with other studies the definition of compliance should be considered. Usually compliance means a history of regular, uninterrupted use of prophylactic drugs during travel and for four or more weeks after leaving the malarious area or until the onset of symptoms of malaria. Lobel et al found good compliance in $52 \%$ of 3469 travellers to Kenya staying less than three weeks but lower percentages for those staying more than three weeks. ${ }^{10}$ Steffen et al reported that $57 \%$ of the travellers (defined as being abroad for less than three months) were compliant, compared with 29 of those who spent 3-12 months abroad. ${ }^{11}$ Behrens reported higher non-compliance in patients admitted with falciparum malaria. ${ }^{13}$

It was not possible to confirm compliance by measuring drug concentrations in blood: blood spots were received from only two thirds of the subjects; proguanil concentration could not be estimated; some blood spots contained less than $50 \mu \mathrm{l}$; and there were difficulties with extraction from filter paper. In 13 blood spots tested, chloroquine concentrations were adequate in six $(46 \%)$, which is in accordance with the figures above.

Compliance was confirmed in only one of the seven patients with a prophylaxis failure and chloroquine in the regimen. Thus, one prophylaxis failure was proved to be a breakthrough. Confirming compliance by measuring chloroquine concentrations in whole blood (not used in previous studies and incomplete in our study) contributed little to the results. As far as we could measure, compliance seemed far less than might be expected from the participants, who had agreed to

\begin{tabular}{l} 
Clinical implications \\
\hline Owing to the rise and spread of drug resistant \\
Plasmodium falciparum, it is increasingly \\
difficult to give recommendations on malaria \\
chemoprophylaxis for areas with high transmis- \\
sion \\
A balance has to be found between risk of \\
infection and risk of adverse reactions \\
- In this study, which compared different \\
regimens of well known, fairly non-toxic drugs, \\
prophylaxis failures occurred in less than $1 \%$ of \\
the participants \\
- Compliance with chemoprophylaxis is still \\
quite poor \\
- Failure of compliance should be clearly dis- \\
tinguished from failure of chemoprophylaxis
\end{tabular}

take part in the study. It nevertheless indicates that the data on prophylaxis failures previously reported might be overestimated. On the other hand, not adjusting for compliance is probably a better reflection of the reality.

\section{RECOMMENDATIONS}

To our knowledge, our study is the first to compare chloroquine $300 \mathrm{mg}$ weekly and proguanil $100 \mathrm{mg}$ daily (the national Dutch recommendation at the time the study was started) with chloroquine combined with proguanil $200 \mathrm{mg}$ daily. No difference in the risk of prophylaxis failure between these regimens was found. To attain uniformity with Europe, however, in 1992 the Dutch recommendation was changed to proguanil $200 \mathrm{mg}$ for travellers to east, southern, and central Africa; chemoprophylaxis with mefloquine was recommended for visits to west Africa. In the recently published recommendations for travellers from the United Kingdom mefloquine is preferred for visits to east and central Africa, with the chloroquine-proguanil combination still considered second best. ${ }^{14}$

In view of the low risk of prophylaxis failures in travellers using the chloroquine-proguanil combination our results support the national recommendation for Dutch travellers to east, central, and southern Africa. Where chloroquine is contraindicated, prophylaxis with proguanil alone $(200 \mathrm{mg} /$ day $)$ can be considered.

We thank the staff of the vaccination centres: the Academic Medical Centre, Amsterdam; the municipal health services of Amsterdam, Utrecht, and Rotterdam; and the University Hospital, Leiden. We also thank the late Jan de Groot, Janna Westerhuis, and Annemarie van Ooik for their part in the recruitment of participants at the Academic Medical Centre. We acknowledge the contribution of the staff of the vaccination centres of the municipal health services in Amsterdam Utrecht, and Rotterdam and of the University Hospital in Leiden. We are very grateful to Lies Huijgen for the examination of all blood slides; to Madeleine de Wit for measurements from filter papers; to Teunis Eggelte for his support and for suggesting the use of filter paper blood spots and the preparation of the filter papers; to Irene Struiksma for extensive secretarial assistance; to Anne Leentvaar-Kuijpers for critical reading of the text; and to Hans Oosting for statistical advice. ICI Pharmaceuticals kindly supplied proguanil hydrochloride, and Rhone-Poulenc kindly supplied chloroquine. The study received a grant from the Department of Infectious Diseases, Ministry of Health, Welfare, and Cultural Affairs.

1 Wetesteyn JCFM, de Geus A. Chloroquine-resistant falciparum malaria imported into the Netherlands. Bull WHO 1985;63:101-8.

2 Philips-Howard PA, Bradley DJ, Blaze M, Hurn M. Malaria in Britain: 1977 86. BMF 1988;296:245-8.

3 Lackritz EM, Lobel HO, Howell J, Bloland P, Campbell CC. Imported Plasmodium falciparum malaria in American travelers to Africa. $¥ A M A$ 1991;265:383-5.

4 Prophylaxis against malaria for travellers from the United Kingdom. Report of meetings convened by the Malaria Reference Laboratory and the Ros Institute. $B M \mp$ 1989;299:1087-9.

5 Philips-Howard PA, Radalowicz A, Mitchell J, Bradley DJ. Risk of malaria in British residents returning from malarious areas. $B M \mathcal{f} 1990 ; 300: 499-503$.

6 Development of recommendations for the protection of short stay travellers to malaria endemic areas: memorandum from two WHO meetings. Bull WHO 1988;66:177-96.

7 World Health Organisation International travel and health. Geneva: WHO, 1991.

8 McLarty DG, Webber RH, Jaatinen M, Kihamia CH, Murru M, Kumano M et al. Chemoprophylaxis of malaria in non-immune residents in Dar es et al. Chemoprophylaxis of

9 Rombo L, Bergquist Y, Hellgren U. Chloroquine and desethyl-chloroquine concentrations during regular long-term malaria prophylaxis. Bull WHO 1987;65:879-83.

10 Lobel HO, Philips-Howard PA, Brandling-Bennett AD, Steffen R, Campbell $\mathrm{CC}$, Huong $\mathrm{AY}$, et al. Malaria incidence and prevention among European and North American travellers to Kenya. Bull WHO 1990;68:209-15.

11 Steffen R, Heusser R, Maechler R, Bruppacher R, Naef U, Chen D, et al. Malaria chemoprophylaxis among European tourists in tropical Africa: use, adverse reactions, and efficacy. Bull WHO 1990;68:313-22.

12 Fogh S, Schapira A, Bygbjerg IC, Jepsen S, Mordhorst CH, Kuijlen K, et al. Malaria chemoprophylaxis in travellers to east Africa: a comparative prospective study of chloroquine plus proguanil with chloroquine with prospective study of chloroquine plus proguanil
sulfadoxine-pyrimethamine. $B M 71988 ; 296: 820-2$.

13 Behrens RH. Chloroquine and proguanil prophylaxis in travellers to Kenya. Lancet 1992;339:63.

14 Prophylaxis against malaria for travellers from the United Kingdom. $B M$ 1993;306:1247-52.

(Accepted 12 August 1993) 